\title{
Fault detection based on ROCOV in a multi-terminal HVDC grid
}

\author{
M.J. Pérez Molina ${ }^{1}$, P. Eguia Lopez ${ }^{1}$, D.M. Larruskain ${ }^{1}$, A. Etxegarai ${ }^{1}$, S. Apiñaniz-Apiñaniz ${ }^{2}$ \\ ${ }^{1}$ Department of Electrical Engineering, Faculty of Engineering of Bilbao, Universidad del País Vasco UPV/EHU \\ Alameda Urquijo s/n, 48013 Bilbao (Spain) \\ Phone/Fax number: +0034 946017332 , e-mail: mariajose.perez@ehu.eus \\ 2 Energy Unit, Tecnalia \\ Parque Tecnológico de Vizcaya, Edificio 700, 48160 Derio (Spain) \\ Phone/Fax number: +0034 986812685
}

\begin{abstract}
Protection of a meshed VSC-HVDC grid is a challenge due to the behaviour of DC current and voltage signals during fault conditions. Protection systems must operate in a very short time range. Since fault detection should be very fast, local measurement based algorithms are mostly used; communication based algorithms lack the needed speed as a result of the communication time delay. This way, a ROCOV algorithm is proposed in this paper. This algorithm is analysed for different fault conditions.
\end{abstract}

Key words. HVDC grid, ROCOV, fault detection, protection system, VSC

\section{Introduction}

Nowadays, High Voltage Direct Current (HVDC) grids are getting more relevance worldwide due to their advantageous characteristics when compared with HVAC:

- Lower transmission losses over the same power transfer capacity [1]-[4].

- Lower costs over long transmission distances [1], [3], [4].

- Enable to use underground or submarine cables over long distances since there is no capacitive effect [2], [4].

- Capability of interconnecting asynchronous grids [2]-[4].

- Power flow controllability enables better grid stability under AC transients [1], [4].

- Voltage source converters (VSCs) are suitable for building multi-terminal HVDC grids [4], [5].

- VSCs have the capability of operating on weak AC grid conditions [2], [4], [5].

- Flexibility of VSCs enables the transmission of power from fluctuating and renewable power sources [4].
- Better HVAC power quality and lower flicker due to the controllability of the $\mathrm{AC}$ voltage and frequency outputs from VSCs [1], [4].

- Capability of independently controlling the active and reactive power [2], [6].

There are several point-to-point (P2P) HVDC links operating and transmitting power through very long distances in different parts of the world; however, it is still challenging to evolve from P2P to a multi-terminal (MT) HVDC grid, especially in terms of protection systems [7]. In P2P links the circuit breakers (CBs) are located in the $\mathrm{AC}$ side, consequently during fault conditions the entire link is de-energised. This strategy is not desirable for an entire MT-HVDC grid, it is a more optimal option to isolate only the faulty part of the grid [8].

Moreover, when a fault occurs in a HVDC line, due to the small line resistance, the DC current increases fast to very high levels and the DC voltage drops almost instantaneously to zero. This is very dangerous for the power electronic devices (IGBTs) of the Voltage Source Converters (VSC) since they cannot withstand very high currents [9].

Thus, to isolate faulty parts of the grid and to avoid damage on the IGBTs, HVDC CBs as well as accurate and fast enough fault detection algorithms must be developed [10]. Furthermore, the protection system has to operate fast, in the order of less than 10 milliseconds [11] to avoid damage on components.

Hence, local measurement based algorithms are more common in HVDC protection systems than communication based algorithms since they present better operation times. Communication based algorithms have to compare the measurements taken at both ends of its protection zone; they are limited by the communication time delay [12] which is proportional to the cable length. Thus, they are more appropriate for short transmission distances than for very long ones [13], as a backup system [14] or for high 
impedance fault conditions [15]. Conversely, local measurement based algorithms are faster since they only work with the measurements from one of the ends of the protection zone but they are less selective [16].

Additionally, since there is no zero crossing in DC grids [17], HVDC CBs that can create this condition and that have the capability of interrupting high current [18] and dissipating the energy stored in the grid during fault conditions [19] are needed. Nowadays, the most common HVDC CB types are mechanical, solid-state and hybrid $\mathrm{CBs}$, they have operation times of 5-10 ms, $1 \mathrm{~ms}$ and 2-5 ms, respectively [1], [6].

Inductive reactors are usually placed at both ends of the links in order to limit the rate of rise of the current below the current interruption capability of the HVDC CBs. These inductors also delimit the borders of the protection zones. This way, the selectivity of local measurement based algorithms is improved. The size of these components have to be carefully selected according to the selected algorithm and the characteristics of the protected grid since it could affect the system stability [20].

Likewise, a fault clearing strategy must be selected according to the protection equipment implemented in the system. This determines the severity of the fault impact on the HVDC and AC systems [17], [21]. A non-selective strategy is based on shutting down the entire system after fault detection by AC CBs. Afterwards, DC disconnectors isolate the faulty part and the system is reenergised. HVDC CBs are located at both ends of each link of the system in a full-selective strategy. This way, only the faulty part of the system is disconnected and the healthy part remain operating unaffected. A combination of these two strategies, named partially-selective strategy, is sometimes selected. In this case, the system in divided into protection zones interconnected by lines/cables. HVDC $\mathrm{CBs}$ or $\mathrm{DC} / \mathrm{DC}$ converters are placed in these links to isolate the protection zones in case a fault is detected. Then, AC CBs of the affected zone operate and shut it down. Finally, DC disconnectors isolate the faulty part inside the protection zone and the healthy ones are reenergised.

\section{Rate of Change of Voltage}

The Rate of Change of Voltage (ROCOV) algorithm uses local measurements of the DC voltage signal. The DC voltage derivative is calculated, as in (1).

$$
\operatorname{ROCOV}=\frac{\Delta v}{\Delta t}=\frac{v_{2}-V_{1}}{t_{2}-t_{1}}
$$

In normal conditions, the values of the ROCOV are close to zero since the DC voltage is constant but, during fault conditions, the DC voltage drops sharply, then, the calculated values of ROCOV will increase. Hence, ROCOV is a good feature to use for discrimination of fault conditions from normal operation changes [11].

Theoretically, the value of the derivative is zero during normal operation and will change drastically during fault conditions. Nevertheless, the value is not zero during normal operation due to disturbances and fluctuations. Hence, the derivative value must be compared with a determined threshold for better selectivity [21].

Due to the almost instantaneous voltage collapse, the ROCOV presents very high values. Hence, the operation speed of this algorithm is very fast [21], [22].

The performance of the ROCOV algorithm depends on the threshold used to discriminate fault conditions (internal and external to the protection zone) and normal operating conditions. The value of this threshold is selected according to the grid conditions and through simulations. A higher threshold value increases the selectivity at the expense of the sensitivity. Therefore, a trade-off value between these two requirements must be selected.

This detection method is abundant on the literature. A ROCOV based main protection system for a 9-terminal HVDC grid is presented in [23]. A main and busbar protection system for a 3-terminal HVDC grid is proposed in [24], fault discrimination is achieved comparing the ROCOV at both sides of the terminal inductor; an internal bus fault occurs when the bus side ROCOV is the greatest. The protection system proposed in [25] discriminates between internal and external faults comparing the ROCOV at both sides of the inductors as well; an internal fault occurs when the line side ROCOV is the greatest while the bus side ROCOV is the greatest when an external fault occurs. The limiting inductors placed at both ends of the links delimit the borders of the protection zones, allowing selectivity. A faster protection system is presented in [26] where the ratio between the ROCOV at both sides of the reactor is used as a fault marker; it presents a detection time of 200 microseconds.

The sampling frequency used in this paper to calculate the ROCOV is $10 \mathrm{kHz}$. A threshold of $-0.2 \mathrm{MV} / \mathrm{ms}$ is used to allow fault discrimination.

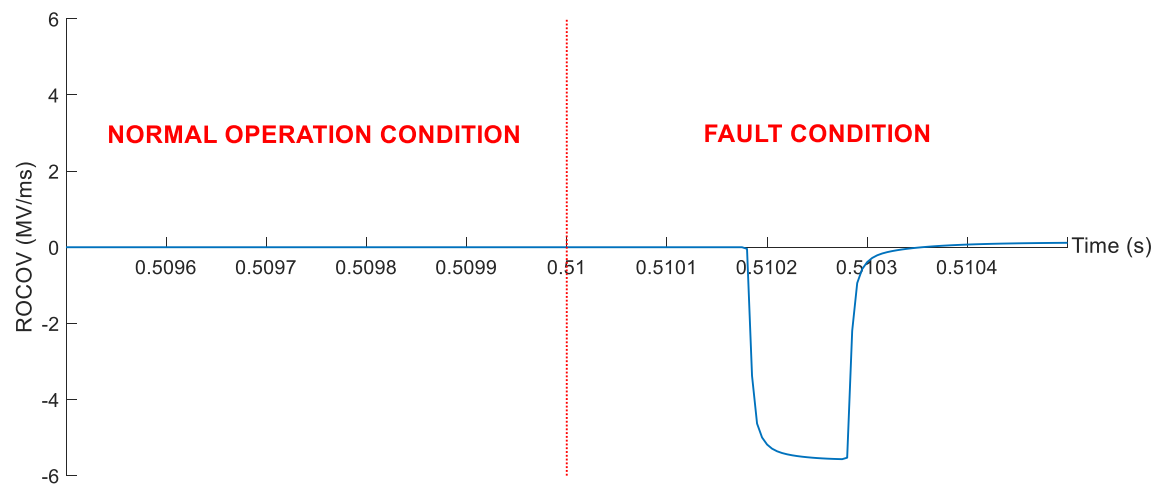

Fig 1. ROCOV variation between normal operation and fault condition. 


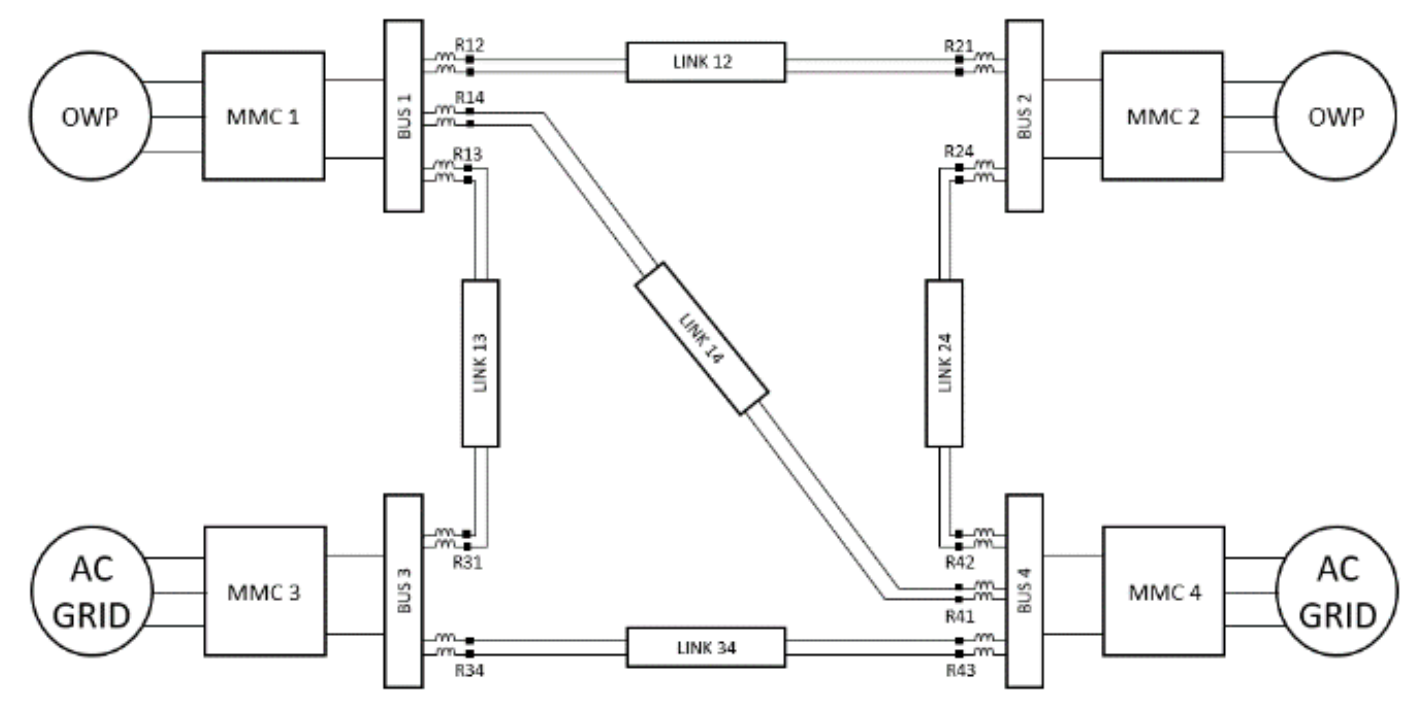

Fig 2. VSC-HVDC grid scheme.

\section{Study Case}

This section summarises the results of the analysis of the performance of the ROCOV algorithm in a multi-terminal HVDC grid. Several fault conditions where simulated using PSCAD software. The fault conditions were located in different links varying the fault type, distance and resistance.

\subsection{Multi-terminal grid}

A 4-terminal VSC-HVDC grid is modelled in PSCAD software. The model is available in [27]. Four half-bridge modular multilevel converters (MMC) interconnect two offshore wind power plants with two onshore AC grids through five cables. The configuration of the system is symmetric monopole. Links 12 and 34 are $100 \mathrm{~km}$ long, links 13 and 14 have a length of $200 \mathrm{~km}$ while the length of link 34 is $150 \mathrm{~km}$. MMCs 1,2 and 3 present a rated power of 900 MVA while the rated power of MMC 4 is 1200 MVA. System voltage is $320 \mathrm{kV}$.

A full-selective fault clearing strategy is adopted. Then, each protection zone is limited at both ends by a hybrid HVDC circuit breaker (CB) in series with a $0.1 \mathrm{H}$ inductor, as it is shown in Figure 2. This way, there are five protection zones, one per link. The operation time of the HVDC CBs is assumed to be 2 milliseconds.

\subsection{Fault Distance}

Several fault conditions are simulated varying the fault distance. Pole-to-pole (PtP), positive-pole-to-ground (PPtG) and negative-pole-to-ground (NPtG) faults are simulated in every link of the grid.

All the fault conditions simulated in this subsection present a fault resistance of $0.01 \Omega$.

The data on Table I is related to one of the two relays located on a link, due to limited space. This way, for link "AB", the data shown in Table I, is measured in relay " $\mathrm{A}$ ". Likewise, the fault locations shown are related to bus A.

The ROCOV algorithm detects every simulated fault condition. As it can be extracted from Table I, the ROCOV detection time increases with the fault distance since the fault traveling wave takes a longer time to arrive to the relay point. However, the detection speed is very fast anyway. ROCOV algorithm takes around 1 millisecond to detect remote faults and a few hundreds of microseconds to detect near faults. On the other hand, the HVDC CBs interrupt currents around 3-6 kA.

Table I. - Operation parameters of ROCOV algorithm for different fault locations.

\begin{tabular}{|c|c|c|c|c|c|}
\hline Link & Fault Type & Fault Distance (km) & Detection Time (ms) & Operation Time (ms) & Interrupted Current (kA) \\
\hline \multirow{3}{*}{12} & PtP & 35 & 0.20 & 2.20 & 4.81 \\
\hline & PPtG & 60 & 0.34 & 2.34 & 4.60 \\
\hline & NPtG & 82 & 0.46 & 2.46 & 4.06 \\
\hline \multirow{3}{*}{13} & PtP & 150 & 0.83 & 2.83 & 6.12 \\
\hline & PPtG & 20 & 0.12 & 2.12 & 5.26 \\
\hline & NPtG & 72 & 0.40 & 2.40 & 5.34 \\
\hline \multirow{3}{*}{14} & PtP & 195 & 1.08 & 3.08 & 5.98 \\
\hline & PPtG & 143 & 0.79 & 2.79 & 5.23 \\
\hline & NPtG & 12 & 0.08 & 2.08 & 5.01 \\
\hline \multirow{3}{*}{24} & $\mathrm{PtP}$ & 7 & 0.05 & 2.05 & 5.71 \\
\hline & PPtG & 121 & 0.67 & 2.67 & 4.33 \\
\hline & NPtG & 32 & 0.19 & 2.19 & 4.48 \\
\hline \multirow{3}{*}{34} & PtP & 25 & 0.15 & 2.15 & 4.45 \\
\hline & PPtG & 50 & 0.28 & 2.28 & 3.22 \\
\hline & NPtG & 83 & 0.46 & 2.46 & 3.02 \\
\hline
\end{tabular}


Table II. - Operation parameters of ROCOV algorithm for different fault locations and resistances.

\begin{tabular}{|c|c|c|c|c|c|c|}
\hline Link & Fault Type & Fault Distance $(\mathrm{km})$ & Fault Resistance $(\Omega)$ & Detection Time (ms) & Operation Time (ms) & Interrupted Current (kA) \\
\hline \multirow{3}{*}{12} & PtP & 35 & 10 & 0.20 & 2.20 & 4.14 \\
\hline & PPtG & 60 & 50 & 0.34 & 2.34 & 2.13 \\
\hline & NPtG & 82 & 100 & 0.46 & 2.46 & 1.37 \\
\hline \multirow{3}{*}{13} & PtP & 150 & 15 & 0.83 & 2.83 & 5.26 \\
\hline & PPtG & 20 & 25 & 0.12 & 2.12 & 3.31 \\
\hline & NPtG & 72 & 125 & 0.41 & 2.41 & 1.77 \\
\hline \multirow{3}{*}{14} & PtP & 195 & 150 & 1.09 & 3.09 & 2.20 \\
\hline & PPtG & 143 & 110 & 0.80 & 2.80 & 1.69 \\
\hline & NPtG & 12 & 45 & 0.08 & 2.08 & 2.44 \\
\hline \multirow{3}{*}{24} & $\mathrm{PtP}$ & 7 & 70 & 0.05 & 2.05 & 3.45 \\
\hline & PPtG & 121 & 120 & 0.68 & 2.68 & 1.83 \\
\hline & NPtG & 32 & 30 & 0.19 & 2.19 & 3.13 \\
\hline \multirow{3}{*}{34} & $\mathrm{PtP}$ & 25 & 200 & 0.15 & 2.15 & 1.15 \\
\hline & PPtG & 50 & 80 & 0.29 & 2.29 & 1.04 \\
\hline & NPtG & 83 & 5 & 0.46 & 2.46 & 2.75 \\
\hline
\end{tabular}

\subsection{Fault Resistance}

The performance of the ROCOV algorithm is analysed for different fault resistances up to $200 \Omega$. The fault distances are the same than those simulated in subsection 3.2 but varying the fault resistance.

Just like in subsection 3.2, the data on Table II is just related to one of the two relays located on a link.

Table II shows a summary of the results of the simulations. The ROCOV algorithm detects every fault condition simulated regardless of the fault resistance. Thus, this algorithm shows a great performance against resistive faults since $99.9 \%$ of the faults, that usually occurs in a grid, show a resistance lower than $200 \Omega$ [28].

In comparison with the case of $0.01 \Omega$ fault resistance, the ROCOV takes the same time detecting the faults regardless of the fault resistance but the HVDC CBs have to interrupt lower currents during high resistance fault conditions, around 1 to $5 \mathrm{kA}$.

\section{Conclusion}

Nowadays, HVDC transmission alternative is getting more relevance. However, due to the fast increase of the current and the sharp collapse of the voltage during fault conditions, fast detection algorithms and HVDC circuit breaker must be developed.

This paper proposes a protection system for multi-terminal grids based on a full-selective fault clearing strategy using hybrid HVDC CBs located at both ends of each link in series with $0.1 \mathrm{H}$ inductive reactors. A local method is used for fault detection based on the rate of change of voltage. The performance of this algorithm is tested through simulations in PSCAD software. Different fault conditions varying the fault distance and resistance on different links were simulated. The ROCOV algorithms presented a reliable and selective performance to all the conditions simulated; even fault conditions up to $200 \Omega$ were properly detected. The ROCOV operation time is from a few ten of microseconds for close faults to around 1 millisecond for remote faults.

\section{Acknowledgement}

The authors gratefully acknowledge the support from the Spanish Ministry of Economy, Industry and Competitiveness (project ENE2016-79145-R AEI/FEDER, UE), the Basque Government (GISEL research group IT1191-19), as well as from the University of the Basque Country UPV/EHU (research group funding GIU18/181).

\section{References}

[1] M. Farhadi and O. A. Mohammed, "Protection of multiterminal and distributed DC systems: Design challenges and techniques," Electric Power Systems Research, vol. 143, pp. 715-727, 2017. DOI: //doi.org/10.1016/j.epsr.2016.10.038.

[2] S. Le Blond, R. Bertho, D. V. Coury and J. C. M. Vieira, "Design of protection schemes for multi-terminal HVDC systems," Renewable and Sustainable Energy Reviews, vol. 56, pp. 965-974, 2016. DOI: //doi.org/10.1016/j.rser.2015.12.025.

[3] L. Shang and W. Liang, "The review of high voltage DC transmission lines fault location," International Journal of Computer, Consumer and Control (IJ3C), vol. 3, (4), pp. 21 28,2014

[4] O. Heyman, A. Sweden and L. Weimers, "HVDC-A key solution in future transmission systems," 2010. Available: https://www.researchgate.net/publication/229000667_HVD C-A_key_solution_in_future_transmission_systems (accessed on 16 December 2019).

[5] J. Candelaria and J. Park, "VSC-HVDC system protection: A review of current methods," in 2011 IEEE/PES Power Systems Conference and Exposition, Phoenix, AZ, USA, 2023 March 2011. DOI: 10.1109/PSCE.2011.5772604.

[6] E. Spahic, D. Ergin, F. Schettler, J. Dorn and C. Petino, "A closer look at protection concepts for DC systems," in Cigré 2016, Paris, France, 21-26 August 2016, 2016.

[7] Q. Yang, S. Le Blond, R. Aggarwal, Y. Wang and J. Li, "New ANN method for multi-terminal HVDC protection relaying," Electric Power Systems Research, vol. 148, pp. 192-201, 2017. DOI: 10.1016/j.epsr.2017.03.024.

[8] K. Sano and M. Takasaki, "A Surgeless Solid-State DC Circuit Breaker for Voltage-Source-Converter-Based HVDC Systems," IEEE Transactions on Industry Applications, vol. 50, (4), pp. 2690-2699, 2014. DOI: 10.1109/TIA.2013.2293819. 
[9] CIGRÉ WG B4.52, "HVDC Grid Feasibility Study," Cigré, 2013. Available: https://e-cigre.org/publication/533-hvdcgrid-feasibility-study (accessed on 19 December 2019).

[10] S. Azazi, M. Sanaye-Pasand, M. Abedini and A. Hasani, "A Traveling-Wave-Based Methodology for Wide-Area Fault Location in Multiterminal DC Systems," IEEE Transactions on Power Delivery, vol. 29, (6), pp. 2552-2560, 2014. DOI: 10.1109/TPWRD.2014.2323356.

[11] R. Li and L. Xu, "Review of DC fault protection for HVDC grids," WIREs Energy and Environment, vol. 7, (2), 2018. DOI: 10.1002/wene.278.

[12] M. J. Pérez-Molina, D. M. Larruskain, P. Eguia Lopez, O. Abarrategi and M. Santos-Mugica, "A comparison of nonunit and unit protection algorithms for HVDC grids," in AEIT HVDC International Conference 2019, Florence, Italy, 9-10 May 2019. DOI: 10.1109/AEIT-HVDC.2019.8740430.

[13] I. Dallas and C. Booth, "Teleprotection in multi-terminal HVDC supergrids," in 12th IET International Conference on Developments in Power System Protection (DPSP 2014), Copenhagen, Denmark, 31 March-3 April 2014, 2014, pp. 16. DOI: $10.1049 / \mathrm{cp} .2014 .0015$.

[14] D. Naidoo and N. M. Ijumba, "HVDC line protection for the proposed future HVDC systems," in 2004 International Conference on Power System Technology. PowerCon 2004. Singapore, Singapore, 21-24 Nov. 2004, 2005, pp. 1327 1332 Vol.2. DOI: 10.1109/ICPST.2004.1460207.

[15] W. Leterme, J. Beerten and D. Van Hertem, "Nonunit Protection of HVDC Grids With Inductive DC Cable Termination," IEEE Transactions on Power Delivery, vol. 31, (2), pp. 820-828, 2016. DOI: 10.1109/TPWRD.2015.2422145

[16] G. Buigues, V. Valverde, I. Zamora, D. M. Larruskain, O. Abarrategui and A. Iturregi, "DC fault detection in VSCbased HVDC grids used for the integration of renewable energies," in 2015 International Conference on Clean Electrical Power (ICCEP), Taormina, Italy, 16-18 June 2015, 2015, pp. 666-673. DOI: 10.1109/ICCEP.2015.7177591.

[17] W. Leterme, I. Jahn, P. Ruffing, K. Sharifabadi and D. Van Hertem, "Designing for High-Voltage dc Grid Protection: Fault Clearing Strategies and Protection Algorithms," IEEE Power and Energy Magazine, vol. 17, (3), pp. 73-81, 2019. DOI: 10.1109/MPE.2019.2897188

[18] J. Descloux, B. Raison and J. Curis, "Protection strategy for undersea MTDC grids," in 2013 IEEE Grenoble Conference, Grenoble, France, 16-20 June 2013. DOI: 10.1109/PTC.2013.6652286.

[19] M. K. Bucher and C. M. Franck, "Fault Current Interruption in Multiterminal HVDC Networks," IEEE Transactions on
Power Delivery, vol. 31, (1), pp. 87-95, 2016. DOI: 10.1109/TPWRD.2015.2448761.

[20] J. Häfner and B. Jacobson, "Proactive hybrid HVDC breakers - A key innovation for reliable HVDC grids," in The Electric Power System of the Future - Integrating Supergrids and Microgrids International Symposium, Bologna, Italy, 13-15 September 2011.

[21] I. Jahn, N. Johannesson and S. Norrga, "Survey of methods for selective DC fault detection in MTDC grids," in 13th IET International Conference on $\mathrm{AC}$ and $\mathrm{DC}$ Power Transmission (ACDC 2017), Manchester, UK, 14-16 February 2017, 2017, pp. 1-7. DOI: 10.1049/cp.2017.0041.

[22] V. Psaras, A. Emhemed, G. Adam and G. M. Burt, "Review and evaluation of the state of the art of DC fault detection for HVDC grids," in 2018 53rd International Universities Power Engineering Conference (UPEC), Glasgow, Scotland, 4-7 September 2018. DOI: 10.1109/UPEC.2018.8541961.

[23] J. Sneath and A. D. Rajapakse, "DC fault protection of a nine-terminal MMC HVDC grid," in 11th IET International Conference on AC and DC Power Transmission, Birmingham, UK, 10-12 February 2015, 2015, pp. 1-8. DOI: 10.1049/cp.2015.0082.

[24] J. Sneath and A. D. Rajapakse, "Fault Detection and Interruption in an Earthed HVDC Grid Using ROCOV and Hybrid DC Breakers," IEEE Transactions on Power Delivery, vol. 31, (3), pp. 973-981, 2016. DOI: 10.1109/TPWRD.2014.2364547.

[25] N. M. Haleem and A. D. Rajapakse, "Application of new directional logic to improve DC side fault discrimination for high resistance faults in HVDC grids," Journal of Modern Power Systems and Clean Energy, vol. 5, (4), pp. 560-573, 2017. DOI: $10.1007 / \mathrm{s} 40565-017-0301-4$.

[26] N. Haleem and A. Rajapkse D., "Local measurement based ultra-fast directional ROCOV scheme for protecting Bi-pole HVDC grids with a metallic return conductor," International Journal of Electrical Power \& Energy Systems, vol. 98, pp. 323-330, 2018. DOI: 10.1016/j.ijepes.2017.11.033.

[27] W. Leterme, N. Ahmed, J. Beerten, L. Ängquist, D. V. Hertem and S. Norrga, "A new HVDC grid test system for HVDC grid dynamics and protection studies in EMT-type software," in 11th IET International Conference on AC and DC Power Transmission, Birmingham, UK, 10-12 Feb. 2015, 2015, DOI: 10.1049/cp.2015.0068.

[28] J. Descloux, P. Rault, S. Nguefeu, J. Curis, X. Guillaud, F. Colas and B. Raison, "HVDC meshed grid: Control and protection of a multi-terminal HVDC system," in CIGRÉ Session Paris, Paris, France, 26-31 August 2012, 2012, pp. 10. 